\title{
Giant Cells in Health and Disease-A Review
}

\author{
Sonal Gupta ${ }^{1}$, Harshminder Kaur ${ }^{2}$, Parvind Gumber ${ }^{1}$, Nida Fahmi ${ }^{3}$, Kanchan Sharma ${ }^{4}$, Arvind Gumber ${ }^{5}$ \\ ${ }^{1}$ Senior Lecturer, Department of Oral Pathology, Mahatma Ghandi dental college and Hospital, Jaipur. \\ ${ }^{2}$ Professor, Department of Oral Pathology, Seema dental college, Rishikesh. Senior Lecturer, Department \\ of Oral Pathology, Jaipur dental college and hospital, Jaipur, Senior Lecturer, Department of Oral \\ Pathology, Rajasthan dental college and hospital,Jaipur, ${ }^{6}$ Consultant,Oral and Maxillofacial surgeon, \\ Karanpur.
}

\begin{abstract}
Macrophages play essential roles in a wide variety of physiological and pathological processes. One of the unique features of these phagocytic leukocytes is their ability to fuse, forming multinucleated giant cells. Multinucleated giant cells are important mediators of tissue remodeling and repair and are also responsible for removal or sequestration of foreign material, intracellular bacteria and non phagocytosable pathogens, such as parasites and fungi. Depending upon the tissue where fusion occurs and the inflammatory result, multinucleated giant cells assume distinctly different phenotypes. Nevertheless, the ultimate outcome is the formation of large cells that can resorb bone tissue (osteolasts) or foreign material and pathogens (giant cells) extracellularly. The present review aims to concisely explain molecular mechanism of formation of giant cells and describes characteristic features of these cells in various diseases.
\end{abstract}

Keywords: Langhan's giant cells; Reed Sternberg cells; Touton giant cell; Xanthoma

Corresponding author: Dr Parvind Gumber, Senior Lecturer, Department of Oral Pathology, Mahatma Ghandi dental college and Hospital,Jaipur. Email: dr.parvindgumber@yahoo.com

This article may be cited as: Gupta S, Kaur H, Gumber P, Fahmi N,Sharma K and Gumber A Giant cells in health nd disease-a review.Int J Com Health and Med Res 2016;2(2):60-65

Article Received: $16-02-16$

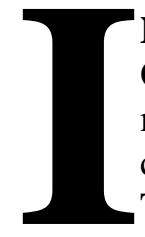

\section{NTRODUCTION}

Observation of tissues under the microscope allows the generalization that cells normally contain a single nucleus. This broad generalization is broken in a relatively small number of specific circumstances. Some tissues regularly contain cells in which several nuclei share the same cytoplasm: skeletal muscle, placenta and bone. The occurrence of polykaryons/ multinucleated giant cells elsewhere is always abnormal. ${ }^{1}$ For over a century, multinucleate giant cells have been recognized in various diseased tissues. A giant cell can be described as an unusually large, huge or gigantic cell; as a large multinucleated often phagocytic cell, cell with more than one nucleus, a multinucleated mass of cytoplasm that is not separated into cells. ${ }^{2}$ Since all giant cell variants
Accepted On: 03-05-2016

are derived from monocyte/macrophage precursors, their morphological and functional heterogeneity seems to be determined by the specific tissue location and local factors present in the milieu where cell fusion occurs. ${ }^{3}$ Giant cells are pathognomonic features of some lesions like central and peripheral giant cell granuloma giant cell fibroma, Hodgkin's lymphoma, etc. There are some lesions where giant cells are the characteristic features but not the pathognomonic feature as in tuberculosis, measeles, xanthomas, HSV infection, etc. ${ }^{4}$

\section{HISTORY}

Muller J (1838) ${ }^{1}$ is credited with their discovery; some years later, both Virchow and Langhans discussed their nature. Langhans dealt in some detail with their role in tuberculous and foreign- 
body reactions and speculated on the mode of their formation. Lambert A (1912) observed the formation of multinucleate giant cells from wandering mononuclear cells, while the Lewises reported the transformation of the mononuclear blood cells of lower vertebrates into giant cells in hanging drop cultures. Since then, several other investigations have provided further evidence for the derivation of giant cells from mononuclear phagocytes. $^{5}$

\section{Classification of Giant Cells}

Giant cells can be classified into several morphological variants depending upon the arrangement and composition of organelles, functional characteristics and pathology involved.

I. Classification based on arrangement, composition of organelles and function:

A. Haythorn $(1929)^{6}$

1. Langhans giant cells (2)Foreign body giant cells (3) Osteoclasts (4) Megakaryocytes (5) Muscle giant cells (6) Giant cells of nervous tissue (7) True tumor giant cells.

B. Quinn MT and Schepetkin IA (2009) $)^{3}$

1. Foreign body giant cells (2) Langhans giant cells (3) Touton giant cells (4) Osteoclast like cells (5) Osteoclasts.

II. Classification based on functional characteristics:

Chattopadhyay $(1995)^{4}$

1. Damaged striated muscle fibres

a. Regenerating sacrolemmal cells in damaged voluntary muscle. (b)Aschoff giant cells in heart muscle (fused myocardial macrophages).

2. Fused fibroblasts (as in giant cell fibroma)

3. The osteoclast

4. Tumor giant cells

a. Reed-stern berg cells in Hodgkin's lymphomas. (b) Giant cells in central giant cell granuloma (c) Giant cells in other tumors eg. Carcinoma

5. Fused cells due to viral infections.

a. Epithelial giant cells as in HSV infection. (b)Connective tissue cells as in Measles (Warthin Finkeldey cells).

6. $\quad$ Fused macrophages

a. Due to reaction to foreign bodies (exogenous or endogenous materials) e.g. foreign body giant cell with scattered nuclei (b) Due to reaction to organism as in tuberculosis (Langhans' giant cell) and fungal infections (c) Touton giant cells of xanthoma.

III. Classification based on pathology involved:

A. Cotran, Kumar and Robbins (1994) ${ }^{7}$

1. Giant Cells In Inflammation :

a) Foreign Body giant cells (b) Langhan's giant cells (c)Touton giant cells (d) Aschoff giant cells

2. Giant Cells In Tumor :

a) Tumor giant cells (b)Reed-Sternberg cells (c)Giant cell tumor of bone

B. Varghese I and Prakash A (2011)

1. Microbial Lesions:

a. Tuberculosis (b) Leprosy (c)

Actinomycosis (d) Sarcoidosis

2. Tumor And Tumor Like Lesions:

a. Central giant cell granuloma (b) Peripheral giant cell garnuloma (c) Giant cell fibroma (d) Giant cell tumor (e) Osteosarcomaa (f) Rhabdomyosarcoma (g) Hodgkin's lymphoma 3. Cystic Lesions:

a) Traumatic bone cyst (b)Aneurysmal bone cyst

4. Metabolic Lesions:

a) Hyperparathyrpoidism

5. Osteodystrophic Lesions:

a) Noonan like multiple giant cell lesion syndrome

6. Miscellaneous Lesions:

a) Cherubism (b) Paget's disease (c) Fibrous dysplasia

Types of Giant Cells:

1. Physiologic Giant Cells ${ }^{8}$

Physiological giant cells are the multinucleated giant cells that exist in normal tissues.

eg. Osteoclast in bone, Trophoblast in placenta, Megakaryocytes in bone marrow.

\section{Pathologic Giant Cells}

A. Giant Cell in Inflammation ${ }^{8}$

(i) Foreign Body Giant Cells:

These contain numerous nuclei (up to 100) which are uniform in size and shape resembles nuclei of macrophages. These nuclei are scattered throughout the cytoplasm. These are seen in chronic infective granuloma, leprosy and tuberculosis. When macrophages encounter insoluble materials, they fuse / coalesce to form giant cells. This is the mode of formation of giant cells rather than nuclear division. It has been found that despite the inactive appearing nuclei in these cells, DNA synthesis does occur. Mitotic activity 
too has been associated with these cells mainly in the experimental situation. ${ }^{4,8}$

\section{(ii)Langhan's Giant Cell:}

In this type of cells nuclei are like nuclei of macrophages and epitheloid cells. These nuclei are arranged either around periphery in the form of horseshoe or ring or cluster at the two poles of the giant cell. The fusion of macrophages may give rise to giant cell in response to presence of foreign bodies in tissues which may be living cells (eg. Bacteria or fungi) or nonliving material which in turn may be exogenous (silicates, talc, ligatures etc) or produced in the body (sodium urate crystals, cholesterol, keratin, etc) ${ }^{4,9}$

\section{(iii)Touton Giant Cells:}

The Touton giant cell of Xanthoma are fused foam cells with ring like, wreath shaped arrangement of nuclei. Its peripheral cytoplasm has a foamy or vacuolated appearance and the nuclei surround a central area of clear eosinophilic cytoplasm. ${ }^{4,8}$ These are multinucleated cells with vacuolated cytoplasm due to lipid content.

\section{B. Giant cells in tumors}

(i)Tumor giant Cells:

The tumor giant cells are the large tumor cells with a single huge polymorphic nucleus or having two or more nuclei. These nuclei are hyperchromatic and very large compared to the size of the cell. The inflammatory giant cells like foreign body giant cells or Langerhan's giant cell have normochromatic, small, normal looking nuclei which may be numerous within one cell. Giant cell formation in tumors has been related to degree of anaplasia of tumors. ${ }^{9}$

\section{(ii) Reed Sternberg Cells ${ }^{7}$}

Reed-Sternberg cells (also known as lacunar histiocytes for certain types) are different giant cells found with light microscopy in biopsies from individuals with Hodgkin's lymphoma (also known as Hodgkin's disease; a type of lymphoma) primarily due to EBV, and certain other disorders. They are usually derived from B lymphocytes. The Reed-Sternberg cell is typically binucleated ('owl eyenuclei'), although it may be multinucleated ("pennies on a plate"), with prominent nucleoli. Immunophenotypically, Reed - Sternberg cells are positive for CD15/CD30 and negative for CD45/CD20 both in nodal and extra nodal disease.

(iii) Osteoclastic Giant Cells of Bone Tumors ${ }^{7}$

These tumors have uniform distribution of osteoclastic giant cells spread in the stroma.

\section{Formation of Giant Cells}

Multinucleated giant cells are formed through fusion of monocyte/ macrophages that are recruited to bone (osteoclasts), persistent microbial infections (Langhans cells, immune giant cells) or nonphagocytosable foreign material (foreign body type giant cells). On the whole, macrophage fusion has been shown to involve a number of soluble or membrane bound protein factors that promote hydrophobic contacts between cells and mediate subsequent membrane reorganization and cell fusion. ${ }^{3}$ Multinucleated giant cells seem to form in response to different cytokines and other stimuli. In vitro experiments have shown that the T-helper 2 (TH2) cytokines IL-4 and IL-13, as well as granulocyte macrophage colony stimulating factor (GM-CSF), IL-17A, interferon-g (IFN-g) and lectins, can induce the formation of multinucleated giant cells. Macrophage infection by the facultative intracellular bacterium Burkholderia pseudomallei induces macrophage fusion and B-1 lymphocytes are required for the formation of foreign body giant cells. Macrophage fusion can be induced by different triggers such as Receptor activator of nuclear factor kappa ligand (RANKL) and macrophage colony stimulating factor (M-CSF) for osteoclasts and various cytokines or other factors for multinucleated giant cell. $^{10}$

\section{Molecular Mechanism of Fusion of Macrophages:}

Number of functional steps are hypothesized to be involved in the molecular mechanism of macrophage fusion which are (1) Induction of a Fusion-Competent Status (ii) Chemotaxis (iii) Cell-Cell attachment (iv) Cytoskeletal rearrangements (v) Fusion. To fuse, macrophages have to acquire a fusion-competent status. This fusion program involves enhanced transcription of essential fusion factors and is governed by exogenous stimuli such as IL-4, by DAP12mediated and potentially other signaling pathways and is likely to require macrophage-macrophage contact. Chemotaxis of macrophages towards each other is mediated by the chemokine CCL2. In addition, the other factors that might play role during this process are seven-transmembrane receptors, possibly DC-STAMP; cellular adhesion through E-cadherin and exposure of the phospholipids PtdSer, as well as lipid recognition; surface adhesion through integrins and/or other adhesion factors and cytoskeletal rearrangements 
mediated by the small GTPase RAC1. Chemotaxis and the resulting cell- cell contact are important for fusion, as well as for programming of macrophages. Cytoskeletal rearrangements are also important for fusion, along with formation of a functional multinucleated cell. ${ }^{10}$ Touton giant cells are seen in lesions with high lipid content such as fat necrosis, xanthoma, and xanthogranulomas. ${ }^{3}$ They are formed by fusion of macrophage-derived foam cells. It is proposed that Touton cells develop when the stimulus to cell fusion is accompanied also by a factor stimulating lipid uptake. ${ }^{11}$ Touton giant cells and osteoclasts results from fusion of M1-polarized macrophages, whereas foreign-body giant cells form from fusion of M2-polarized macrophages. ${ }^{3}$ It is now well-established that osteoclasts are of haematopoietic rather than mesenchymal bone stromal cell origin. (Figure 1) Evidence to support this conclusion was initially provided by experiments employing parabiosis or marrow transplants by Walker DG (1973, 1975). ${ }^{12,13}$ Osteoclast precursors derive from bone marrow as early mononuclear macrophages, circulate in blood, and bind to the surface of bone. Mononuclear osteoclasts tightly adhere to bone, and fuse with each other to form multinuclear osteoclasts. The fused cells are re-organized, polarized and construct osteoclast-specific structures. Transcytosis develops from the basal to the apical side of osteoclasts to enable the discharge of dissolved bone debris. Multinucleation tartrate-resistant acid phosphatase (TRAP) activity and the calcitonin receptor (CTR) are available markers to detect osteoclasts, other than their bone resorbing activity. ${ }^{14}$ In bone, multinucleation of macrophages leads to the formation of osteoclasts. ${ }^{15}$

Potential Mechanism of Fusion of Preosteoclasts And Macrophages: (1) Osteoclast precursor cells respond to the osteoclast differentiation factor RANKL, which induces the expression of DCSTAMP. (2) The DC-STAMP-expressing osteoclast becomes the master fusing cell, which can fuse with a DC-STAMP-negative follower cell. (3) The ligand for DC-STAMP may be membrane bound or soluble; a soluble ligand might be released by either of the fusion partners. (4) DC-STAMP ligation may trigger fusion of the two cells directly or may trigger the expression of as yet unknown membrane-bound molecules (' $\mathrm{X}$ ') that mediate fusion. (5) A similar scenario may occur during the formation of giant cells in which macrophages respond to interleukin-4 by inducing the expression of DC-STAMP, which then facilitates fusion. (Figure 2).Megakaryocytes arise from pluripotent Hematopoeitic Stem Cells that develop into 2 types of precursors, burst-forming cells and colony-forming cells, both of which express the CD34 antigen. Development of both cell types continues along an increasingly restricted lineage culminating in the formation of megakaryocyte precursors that develop into megakaryocytes. Thrombopoietin (TPO), the primary regulator of thrombopoiesis, is currently the only known cytokine required for megakaryocytes to maintain a constant platelet mass . TPO is thought to act in conjunction with other factors, including IL-3, IL-6, and IL-11, although these cytokines are not essential for megakaryocyte maturation. ${ }^{16}$

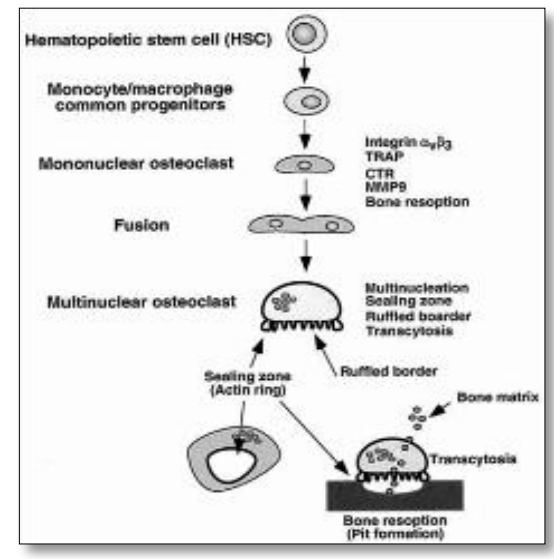

Figure 1: Development Of Osteoclasts From Hematopoietic Stem Cells (Hscs). ${ }^{17}$

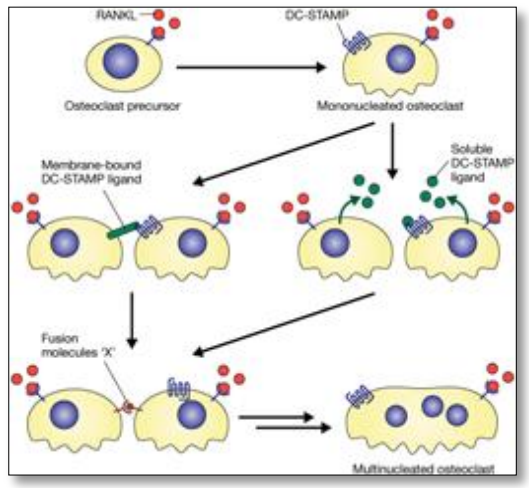

Figure 2: Potential Mechanism of Fusion of Preosteoclasts And Macrophages ${ }^{18}$

Giant cells in diseases

i. Diseases of inflammatory giant cells -1 . Granulomas (i) Immune granulomas (ii) Non Immune Foreign body Granulomas (iii) 
Sarcoidosis. A granuloma consists of a microscopic aggregation of macrophages that are transformed into epithelium like cells surrounded by a collar of mononuclear leukocytes, principally lymphocytes and occasionally plasma cells. Frequently but not invariably, epitheliod cells fuse to form giant cells in the periphery or sometimes in the center of the granulomas. These giant cells may attain diameters of 40 to $50 \mu \mathrm{m}$. They comprise a large mass of cytoplasm containing 20 or more small nuclei arranged peripherally (Langhans type giant cell) or haphazardly ( FBGC). ${ }^{8}$ Giant cells are one of the characteristic features of granulomas and play an important role in regulating granuloma formation by generating cytokines and other mediators. ${ }^{19}$

ii. Lesions containing osteoclasts - (i) Central Giant Cell Granuloma (ii) Paget's Disease - (iii) Cherubism (iv) Osteoblastoma (v) Simple Bone Cyst (vi) Aneurysmal Bone Cyst ${ }^{20}$ (vii) Giant Cell Tumor Of Bone - Giant cell tumors of bone (GCTB); also called giant cell myeloma or osteoclastoma) is a rare and usually benign neoplasm that occurs in long bones. ${ }^{21}$ GCTB are characterized by the presence of stromal fibroblastlike cells, macrophages and multinucleated giant cells that exhibit phenotypic features of osteoclasts. ${ }^{1}$ Giant cell tumor is so named because it contains a profusion of multinucleated osteoclast type giant cells, giving rise to the synonym osteoclastoma. Giant cell tumors are postulated to have a monocyte- macrophage lineage and the giant cells are believed to form via fusion of mononuclear cells. ${ }^{7}$

iii. Disorders related to megakaryocytes - (i) Myelodysplastic syndromes (MDS) (ii) Idiopathic thrombocytopenic purpura (ITP) (iii) Congenital amegakaryocytic thrombocytopenia (iv) Familial essential thrombocythemia (ET)

iv. Giant cell associated tumors - (i) Giant cell reparative granuloma (ii) Vilonodular tenosynovitis (giant cell tumor of soft tissues, giant cell tumor of tendon sheath) - These are tumors of unpredictable behavior and although the giant cells are indistinguishable from foreign body giant cells, the background of mononuclear or " stromal " tumor cells show varying degrees of pleomorphism. (iii) Fibrous histiocytoma (iv) Malignant fibrous histiocytoma - At least 3 types of giant cells exist in Malignant Fibrous Histiocytoma: bizarre giant cells, osteoclast-like giant cells and Touton giant cells. Based on the morphological characteristics, only bizarre giant cells were considered neoplastic cells. The other two types of giant cells may represent reactive cells derived from the normal histiocytic lineage. ${ }^{22}$ (v) Osteoclastoma (vi) Medullary carcinoma of thyroid (vii) Squamous cell carcinoma - Tumorassociated giant cells are seen less predictably in a variety of epithelial neoplasm, when they appear as foreign body giant cells in response to the production of extra cellular material by a carcinoma. They may be seen for example associated with keratin formation in a squamous cell carcinoma, or around deposits of amyloid in medullary carcinoma of the thyroid, and in some areas of other carcinomas of the thyroid as shown by Meissner W and Warren S (1969) ${ }^{23}$, where they may represent a reaction to thyroglobulin production.

v. Reed Sternberg cells of Hodgkins lymphoma Hodgkin's lymphoma is a disease affecting primarily lymph nodes with secondary extranodal spread. It accounts for $1-5 \%$ of head and neck tumors. In the case of classical Hodgkin's lymphoma, the atypical cell is known as a ReedSternberg cell. The neoplastic cells (ReedSternberg cells) make up only about $1 \%$ to $3 \%$ of the cells in the enlarged lymph nodes that characterize this condition. Recent evidence regarding the histogenesis of the Reed-Sternberg cell points to a B-lymphocyte origin. ${ }^{20}$

\section{CONCLUSION}

Inspite of recent advances in understanding the molecular and cellular basis of different types of giant cells formation and function, major challenges remain in appreciating the molecular and cellular similarities and differences of different giant cells. The last 30 years have seen tremendous improvement in our knowledge of giant cell biology, structure and function but inspite of this many mysteries continue to surround the pathogenesis of multinucleated giant cells and the function and significance of their components. Continued research is essential, not only for its theoretical value, but also for its important potential clinical implications. Better knowledge of giant cells will both help to elucidate the pathology and diagnosis of various diseases, such as, central giant cell granuloma, fibrous dysplasia etc and also improve opportunities for therapeutic intervention. 


\section{REFERENCES}

1. Chambers TJ. Multinucleate giant cells. J Pathol 1978;126.

2. Varghese I, Prakash A. Giant cell lesions of oral cavity. OMPJ. 2011;2(1):107-10.

3. Quinn MT, Scheptkin IA. Role of NADPH oxidase in formation and function of mutinulceated giant cells. J Innate Immun 2009;1:509-26.

4. Chattopadhyay A. Giant cells and giant cell lesions of the oral cavity. JIDA 1995;66(1):326-27.

5. Papadimitriou JM, Robertson TA, Walters NI. An analysis of the phagocytic potential of multinucleate foreign body giant cells. Am J Pathol 1975;78(2).

6. Forkner CE. The origin and fate of two types of multinucleated giant cells in the circulating blood. J Exp Med 1930;52.

7. Cotran RS, Kumar V, Robbins SL. Pathologic basis of disease. $5^{\text {th }}$ ed. WB Sunders Company, 1994.

8. Walter JB, Israel MS. General Pathology, $6^{\text {th }}$ ed. Churchill Livingstone, Edinburgh, 1987.

9. Shafer WG, Hine MK, Levy BM. A textbook of Oral Pathology, $4^{\text {th }}$ ed. Phialdelphia: W B Sundars, 1983.

10. Helming L, Gordon S. Molecular mediators of macrophage fusion. Trends Cell Biol 2009;19(10).

11. Aterman K, Remmele W, Smith M. Karl Touton and his "xanthelasmatic giant cell." A selective review of multinucleated giant cells. Am J Dermatopathol 1988 Jun;10(3):257-69.

12. Walker DG. Osteopetrosis curved by temporary parabiosis. Science 1973;180:875.

13. Walker DG. Bone resorption restored in osteopetrotic mice by transplants of normal bone marrow and spleen cells. Science 1975;190:784.

\footnotetext{
Source of support: Nil

Conflict of interest: None declared
}

14. Broadbeck WG, Anderson JM. Giant cell formation and function. Curr Opin Hematol 2009;16(1):53-57.

15. Martinez FO. Alternative activation of macrophages: an immunologic functional perspective. Annu Rev Immunol 2009;27:451.

16. Patel SR, Hartwig JH, Italiano JE. The biogenesis of platelets from megakaryocyte protoplatelets. J Clini Invest 2005;115:334854.

17. Miyamoto T, Suda T. Differentiation and function of osteoclasts. Keio $\mathrm{J}$ Med 2003;52(1):1-7.

18. Vignery A. Macrophage fusion: the making of osteoclasts and giant cells. J Exp Med 2005;202:337-40.

19. Spector WG. Immunologic components of granuloma formation. Epithelioid cells, giant cells, and sarcoidosis. Ann N Y Acad Sci 1976;278: 3-6.

20. Neville BW, Douglas D, Allen CM, Bouquot JE. Oral and maxillofacial pathology. $2^{\text {nd }}$ edition.

21. Goldring SR, Roelke MS, Petrison KK, Bhan AK. Human giant cell tumors of bone identification and characterization of cell types. J Clin Invest 1987;79:483-91.

22. Hatano H, Tokunaga K, Ogose A, Hayami T, Yamagiwa AH, Hotta T et al. The Origin Of Histiocyte Like Cells And Mulinucleated Giant Cells In Malignant Fibrous Histiocytoma: Neoplastic Or Reactive? Pathol Int 1999;49(1):14-22.

23. Meissner W, Warrens A. Tumors of the thyroid gland. In Atlas of tumor pathology, 2nd series 1969

This work is licensed under CC BY: Creative Commons Attribution 4.0 License. 